\title{
Three-dimensional aspects of superficial disseminated porokeratosis with scanning electron microscopy*
}

\author{
Hiram Larangeira de Almeida Jr. ${ }^{1,2}$ \\ Greice Rampon ${ }^{3}$ \\ Nara Moreira Rocha ${ }^{4}$
}

Luciana Boff de Abreu ${ }^{3}$

Ricardo Marques e Silva ${ }^{1}$

DOI: http://dx.doi.org/10.1590/abd1806-4841.20143161

\begin{abstract}
The three-dimensional findings of the surface and from a cross section from a case of disseminated superficial porokeratois using scanning electron microscopy are reported. On the surface of the skin, irregular keratin with a serpiginous distribution was seen. A gross aspect of keratin in the hyperkeratotic wall was also observed and compared to the normal area, in which the release of corneocytes seemed normal. The cross-sectional imaging easily identified the cornoid lamella, with compact keratin surrounded by normal stratum corneum.
\end{abstract}

Keywords: Keratins; Microscopy, electron, scanning; Porokeratosis

\section{INTRODUCTION}

Porokeratoses refer to a group of hereditary or acquired diseases characterized by abnormal epidermal keratinization. They present clinically as annular lesions with hyperkeratinized borders and an atrophic center. Histologically, they are characterized by the presence of a cornoid lamella, which is a thin column of parakeratotic cells raised at the margin of the lesion ${ }^{1-3}$

Six clinical variants were recognized as follows: porokeratosis of Mibelli; disseminated superficial porokeratosis; disseminated superficial actinic porokeratosis; porokeratosis palmaris et plantaris disseminata; linear porokeratosis; and punctate porokeratosis. ${ }^{1,4,5}$
Disseminated superficial porokeratosis (DSP) has been described in association with immunosuppression, such as organ transplants, immunosuppressive therapies, infections and hematopoietic neoplasms. ${ }^{4}$

The objective of this report was to demonstrate three-dimensional findings of a case of DSP using scanning electron microscopy (SEM). We performed a punch biopsy from a 61-year-old man with an 8-year history of renal transplant and hypertension. He was hospitalized for pulmonary tuberculosis and presented the typical lesions of DSP, which appeared 3

\footnotetext{
Received on 23.09.2013

Approved by the Advisory Board and accepted for publication on 04.12.2013.

* Study conducted at the Laboratory of Electronic Microscopy - Universidade Federal de Pelotas (UFPEL) - Pelotas (RS), Brazil.

Conflict of interest: None

Financial funding: None

Universidade Federal de Pelotas (UFPEL) - Pelotas (RS), Brazil.

Universidade Católica de Pelotas (UCPEL) - Pelotas (RS), Brazil.

Pontifícia Universidade Católica do Rio Grande do Sul (PUC-RS) - Porto Alegre (RS), Brazil.

Empresa Brasileira de Pesquisa Agropecuária (EMBRAPA-CPA-CT) - Pelotas (RS), Brazil.

(C)2014 by Anais Brasileiros de Dermatologia
} 
months after the transplantation (Figure 1). A crosssection and the external surface of the specimen were examined.

\section{RESULTS}

Histopathological examination of the punch biopsy material showed the presence of a cornoid lamella and parakeratotic keratinocytes, consistent with the diagnosis of porokeratosis (Figure 2). Scanning electron microscopy was performed on the punch surface, viewed at a $90^{\circ}$ angle and on a crosssectional imaging of the lesion.

On the surface of the skin, irregular keratin with a serpiginous contour on the upper corner of the fragment was observed (Figure 3 ). With a magnification of 120 times, a gross aspect of keratin in the hyperkeratotic wall was observed. With a magnifica-
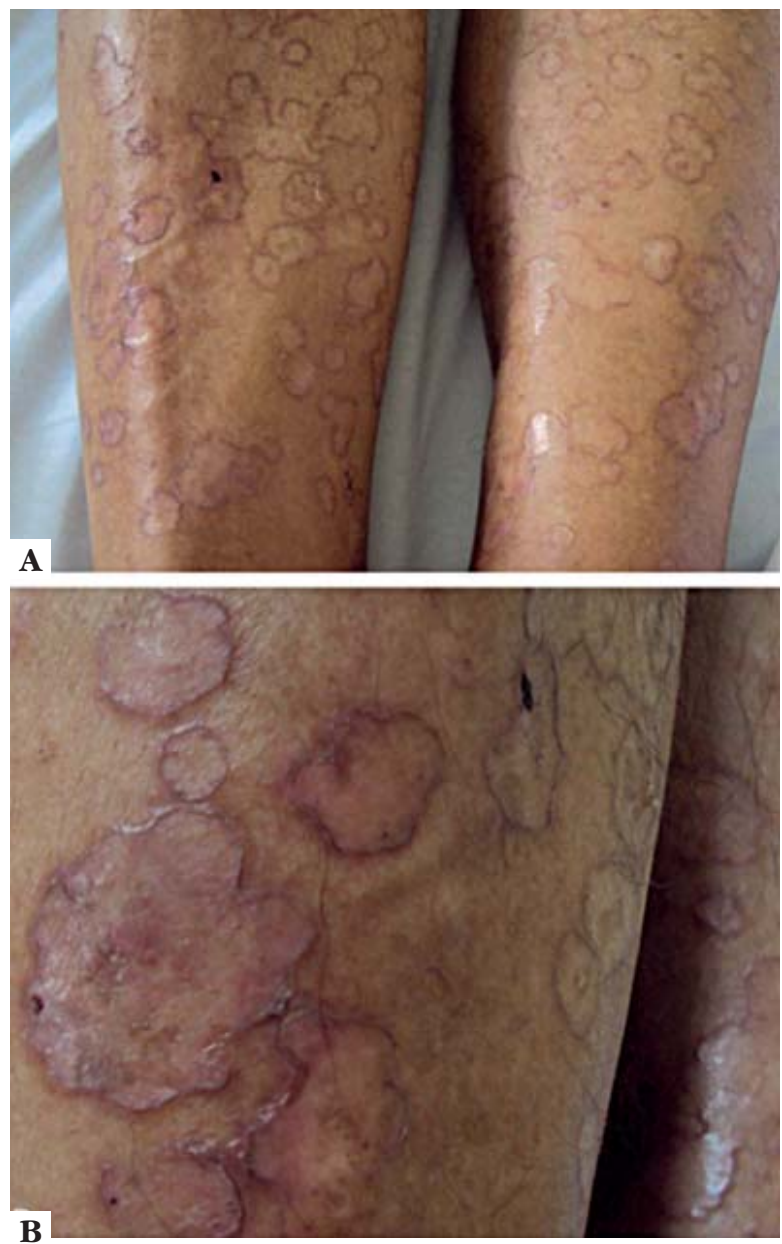

Figure 1: Clinical aspects A. distribution of lesions on the legs. B. detail showing the typical keratotic border
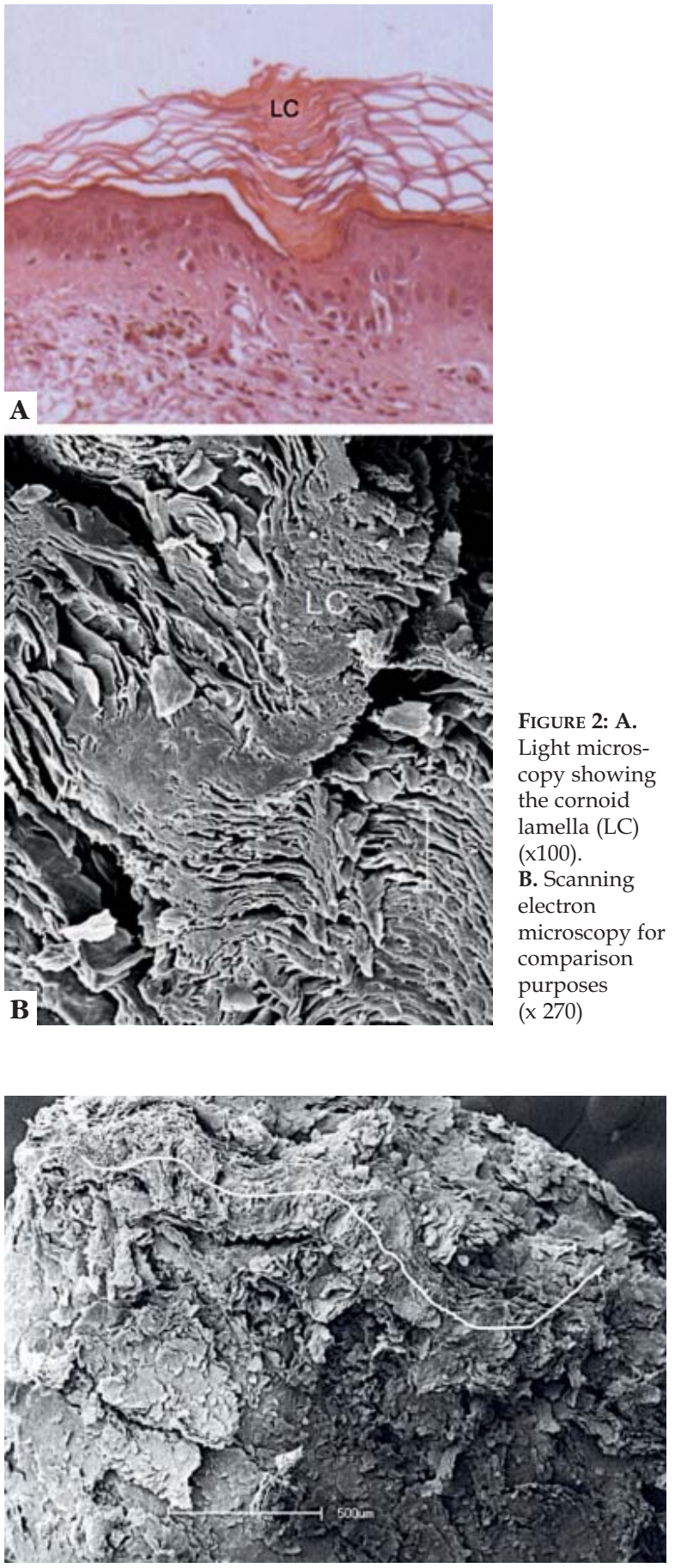

FIGURE 3: Scanning electron microscopy with surface view showing a serpiginous keratotic structure (line) (x 45)

tion of 500 and 600 times the irregular keratin in the lesion could be compared to the normal area in which the release of corneocytes seemed normal (Figure 4). 


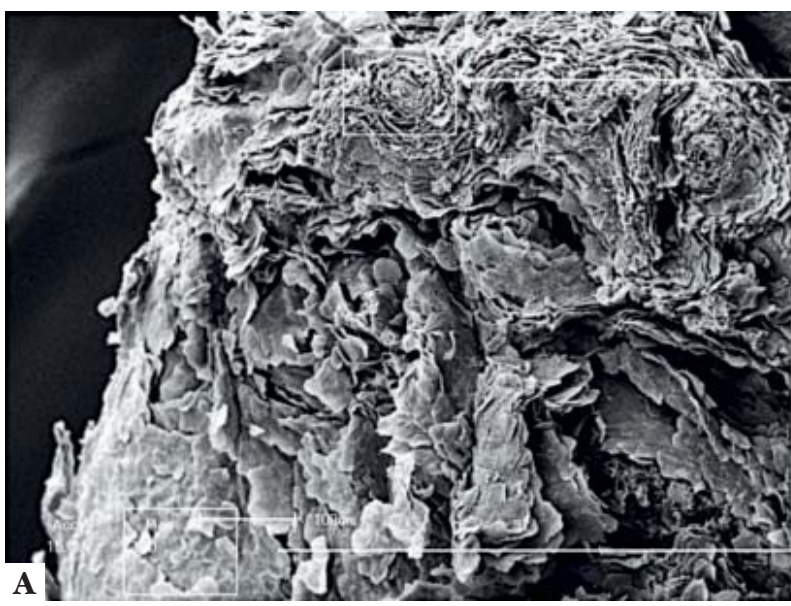

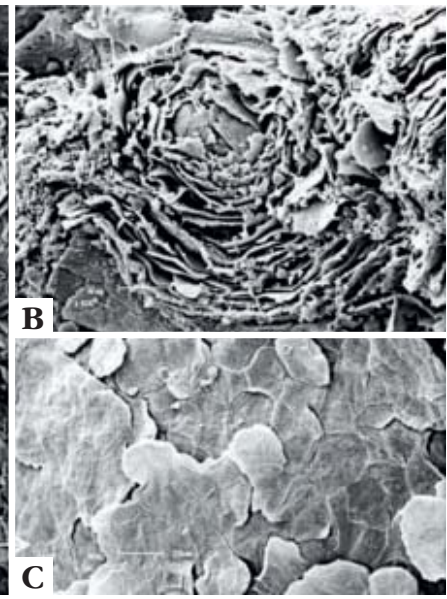

FIGURE 4: Scanning electron microscopy with higher magnification of the surface. A. keratotic area ( $x$ 120). B. detail of the irregular keratinization (x 600). C. detail of the normal area showing normal release of corneocytes (x 500)
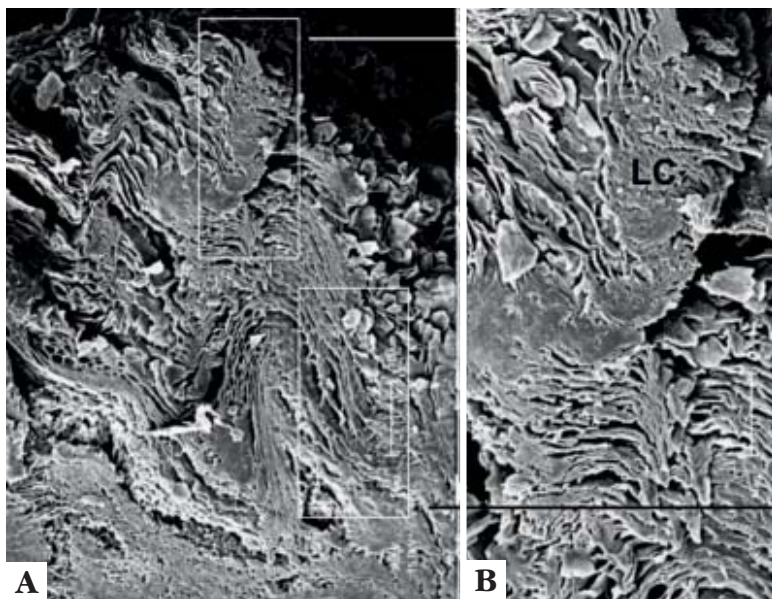

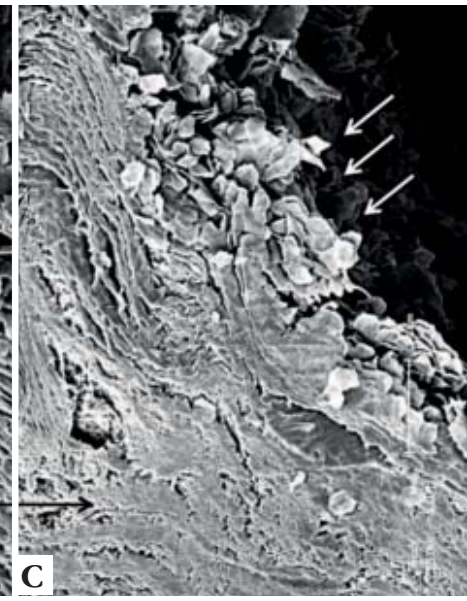

FiguRE 5: Scanning electron microscopy of a cross section. A. raised hyperkeratotic area with cornoid lamella (x120). B. detail of the cornoid lamella showing compact keratin (x270). C. normal area with the "basketball hoop" aspect and normal elimination of corneocytes (arrows) (x 150)
The cross-section with a magnification of 120 times easily identified the presence of cornoid lamella. With a magnification of 270 and 150 times the tightly compacted keratin of the cornoid lamella could be demonstrated, losing the normal "basketball hoop" aspect, viewed on the surrounding keratin, where the normal liberation of corneocytes could also be seen (Figure 5).

\section{DISCUSSION}

The development of porokeratosis lesions is believed to depend on the interaction between genetic and exogenous factors, resulting in peripheral expansion of a mutant clone of keratinocytes. ${ }^{1,6}$ Disseminated superficial porokeratosis has been described in association with immunosuppression such as organ transplant, immunosuppressive therapies, infections and hematopoietic malignancies that appear to function as triggering factors in genetically susceptible patients. ${ }^{1,2,7}$
The incidence of porokeratosis after organ transplants varies considerably among the different studies. In most retrospective studies, it is usually low, ranging from $0.34 \%$ to $3.4 \%{ }^{4}$

The onset of lesions in transplant patients varies between 4 months and 14 years in kidney transplant patients; the lesions appear within 4-5 years. ${ }^{8}$ The onset of lesions is shorter (often less than 3 years) after transplants of other organs (liver, lung, heart, bone marrow) associated with immunosuppression. ${ }^{4}$

In transplant patients, porokeratosis affects the lower limbs and the clinical form most commonly found is DSP. ${ }^{4}$ Decreased number of Langerhans cells expressing HLA-DR antigens have been observed in renal transplant patients, which could be involved in DSP pathogenesis. ${ }^{9}$

The SEM findings overlap the clinical findings, since the hyperkeratotic wall clinically seen was easi- 
ly demonstrated in the surface examination by SEM. They also correlate with light microscopy (Figure 2), demonstrating the compact keratin of the cornoid lamella, which shows a different aspect when compared to the interwoven normal keratin, the "basketball hoop". Similar findings have already been reported. ${ }^{10}$ This technique allows a three-dimensional documentation of its aspects, with high magnifications.

\section{REFERENCES}

1. Rouhani P, Fischer M, Meehan S, Pomeranz MK. Disseminated superficial actinic porokeratosis. Dermatol Online J. 2012;18:24.

2. Shumack SP, Commens CA. Disseminated superficial actinic porokeratosis: a clinical study. J Am Acad Dermatol. 1989;20:1015-22.

3. Jurecka W, Neumann RA, Knobler RM. Porokeratoses: immunohistochemical, light and electron microscopic evaluation. J Am Acad Dermatol. 1991;24:96-101.

4. Kanitakis J, Euvrard S, Faure M, Claudy A. Porokeratosis and immunosuppression. Eur J Dermatol. 1998;8:459-65.

5. Almeida HL Jr, Duquia RP. Linear poroketatosis following Blaschko lines. An Bras Dermatol 2000;75:51-5

6. Raychaudhuri SP, Smoller BR. Porokeratosis in immunosuppressed and nonimmunosuppressed patients. Int J Dermatol. 1992;31:781-2.

7. Torres T, Velho GC, Selores M. Disseminated superficial porokeratosis in a patient with cholangiocarcinoma: a paraneoplastic manifestation? An Bras Dermatol. 2010;85:229-31.

8. Herranz P, Pizarro A, De Lucas R, Robayna MG, Rubio FA, Sanz A, et al. High incidence of porokeratosis in renal transplant recipients. $\mathrm{Br} \mathrm{J}$ Dermatol. 1997;136:176-9.

9. Manganoni AM, Facchetti F, Gavazzoni R. Involvement of epidermal Langerhans cells in porokeratosis of immunosuppressed renal transplant recipients. J Am Acad Dermatol. 1989;21:799-801.

10. Jaworski RC, Versace G, Commens C. Scanning electron microscopy of disseminated superficial actinic porokeratosis. Ultrastruct Pathol. 1990;14:27-30.

How to cite this article: de Almeida Jr. HL, de Abreu LB, Rampon G, Marques e Silva R, Moreira Rocha N. Threedimensional Aspects of Superficial Disseminated Porokeratosis with Scanning Electron Microscopy. An Bras Dermatol. 2014;89(6):988-91. 